\title{
ICTs and Special Education in Kindergarten
}

\author{
http://dx.doi.org/10.3991/ijet.v9i4.3662 \\ Athanasios S. Drigas, and Georgia K. Kokkalia \\ NCSR DEMOKRITOS, Institute of Informatics and Telecommunications, Net Media Lab, Athens, Greece
}

\begin{abstract}
Recent development in the role of special education in kindergarten children includes the use of Information and Communication Technologies (ICTs). ICT nowadays is recognized as a tool that can foster the knowledge and the experiences for this crucial age and the support of specific areas in kindergarten according to the educational perspective and the areas of needs they serve is thought significant. In this paper we present a brief overview of the most representative studies of the last decade (2003-2013) which concentrates on the most frequent difficulties that children face in kindergarten and are supported by ICTs. The effectiveness of ICT in gifted and bilingual children is also presented.
\end{abstract}

Index Terms-kindergarten, ICT, intervention and diagnostic tools, special education, giftedness, bilingualism

\section{INTRODUCTION}

Nowadays kindergarten education is considered and realized to be very important in all over the world. As it is known kindergarten students (4-6 years old; depends on the country's regulations) are very curious to their environment, open to learn, eager to try new activities and therefore kindergarten education is assumed meaningful to enable them to understand their environment [1]. It is thought also important for kindergarteners to experience and learn by doing and thus educating young children is vital for future concept development. The key role of early childhood education for improving educational outcomes across the educational system has gained international recognition during the last decade, especially among the developing countries.

Moreover, is common knowledge that technology and computers are used nearly in all parts of life. As Drigas and Ioannidou [2] state, Information and Communication Technologies (ICTs) is a general term which refers to all kinds of technologies that enable users to access and manipulate information. Education is one of the fields in which ICT is commonly used and its use in kindergarten education is an important issue investigating frequently in last decades [3]. The effect of ICT in education has been studied since the beginning of the 1970s, where educators started to become increasingly convinced that ICTs could support students in formal education.

However, rapid advances in information technology have dramatically transformed the world during the past several decades and the basic requirements of education for the future changed. Knowledge became the most critical resource for social and economic development [4] being able to use computer and Internet effectively, having a qualified education, getting a job and communication skills became prerequisites for human life quality [2]. Thus, access to computers and the World Wide Web is increasingly required for education and employment, as well as for many activities of daily life. While these changes have improved society in many respects, education is one of the basic public service that should be provided for all its citizens considering equality of opportunity by a social-welfare state. Equal opportunities and advantages in computer technology use should be provided for all individuals forming the society [3].

Recently, there has been an increasing emphasis on educating kindergarten children who need special education with the support of ICT and thus this fact has reinforced the use of technology as a mean of overcoming barriers to their learning. There is now a general agreement amongst different specialists that ICT can support a child's skills as well as can create a developmental appropriate learning environment depending on their needs and the curriculum requirements [4]. Many studies have supported the view that ICT can help children who face learning difficulties, have sensory and physical impairments or are considered gifted and bilingual. Existing studies on the introduction of ICTs in kindergarten special education argue that can provide children with additional opportunities for rich learning activities that are relevant to their growth characteristics and have positive effects in regard to their learning difficulties. As a result, ICT can play an essential role in achieving the goals of the kindergarten curriculum in all areas and subjects if the provided developmentally appropriate software applications are embedded in appropriate educational scenarios [5]. Additionally, it has been noted that children who are exposed to high quality learning opportunities at kindergarten, experience less difficulties at their entrance in primary school. In precise, research has supported that children at young ages show advanced cognitive capacities through computer-based activities as, they develop their skills.

The term 'Special Educational Needs' refers to all types of difficulties that can cause problems during the learning process besides that there have been observed various terms amongst countries due to differences in culture, language and ethnicity [6]. Across all types of special educational needs there are also differences in the research methods used as there are models which emphasize needs within the person from a medical, educational or psychological perspective. Our scoping study drew upon national and international publications as well as the research findings of the most representative studies of the last decade which focus on the use of ICT in special education in kindergarten following the categorisation of the Special Education Needs, Code of Practise (2001).

According to the Department for Education and Skills [7], the 'areas of needs' as defined in the 2001 SEN Code of Practice are :

- Communication Interaction

- Sensory and/or Physical, Cognition and Learning 


\section{- Behaviour}

- Emotional and Social Development

(Department for Education and Skills 2001:§7:52, p.85)

This paper will focus on some of the most representative studies which introduce software applications programs for diagnosis and intervention purposes of specific difficulties in kindergarten. In order for these studies to be presented, we created a framework according to the above 'areas of needs' categorization, which consists of four main sections. The first one includes diagnostic and intervention tools regarding children with sensory and physical impairments (visually impaired children, deaf and hearing impaired students, learners with motor impairments), the next one includes the major domains of learning difficulties while the last two categories include children who are gifted and bilingual.

\section{SENSORY AND PHYSICAL IMPAIRMENTS}

In order to guarantee equal opportunities to all students, the accessibility of ICT educational tools is worldwide considered a major issue. Nowadays, visually impaired students can take advantage of a large number of effective assistive technologies besides, they often encounter a number of different accessibility and usability problems [2] . According to the World Health Organization about 314 million individuals are visually impaired worldwide. As a result of the increasing numbers of individuals with a visual impairment, the use of technology in order to access information has been adopted [8]. Nevertheless, the research field about the assessment tests is little due to the fact that vision tests are procedures conducted almost exclusively from doctors and also is difficult for a practitioner or an educator to implement such tests owing to the lack of equipment and training. Despite the above fact, in order to help visually impaired children a number of ICTs have been developed to facilitate learning process and children's everyday life [9].

Raisamo et al [10] introduced a multimodal computer system for kindergarten and primary school students in order to support children's conceptual learning. This system is an e-learning environment consisting of six micro words that present an astronomical phenomenon, which the students can explore independently. There is no need of an adult's presence since the child is guided by imaginary characters, called agents which help it explore the system by making suggestions and asking questions.

Additionally, another research showed that the design, implementation, and usability testing of AudioChile, (a 3D sound virtual environment) can help children with visual disabilities to identify and clearly discriminate environmental sounds and solve everyday problems. The researchers state that children like, accept, use, and are very motivated with the use of the certain software [11].

On the other hand, hearing problems affect also an amount of the special educational needs population as hearing loss symptoms often vary and sometimes occur gradually. In spite of this issue, ICT intervention and support for children with hearing problems is of major significance because children with such kind of problems demand equal access to knowledge and learning resources [12].

A current study [13] presented a mobile application called "Sign my World" which focused to aid deaf chil- dren to learn the Australian Sign Language (Auslan). The application, which is presented as a mobile video game, explores three important concepts (context awareness, personalization and video games principles) in order to support deaf children to be familiar with common nouns and verb signs. The developers claim that the users found it friendly, easy, they enjoyed interacting with the prototype and seemed to learn the incorporated signs after some sessions.

As listening and talking are challenging to kindergarteners with hearing impairments, Yen and Lee [14] introduced a digital interactive storybook based on a voice gesture framework. Using the benefits of portable digital touch screen device, the designers incorporated learning scaffolds and interaction design patterns into the storyline, in order the book guide children to talk and listen with and without guidance. The study stressed that this framework has shown to be a promising platform to assist parents and teachers in shared learning as the children showed significant progress in their language development.

Moreover, a current research presented a Learning System designed for deaf and hard of hearing people [15]. This prototype system offers Greek Sign Language videos in correspondence to all texts in the learning environment and at the same time the students for first time have the opportunity to learn in their own language, the Greek sign language. The system includes also the involvement of the teacher and the administrator. The developers argue that through the appropriate training the users evaluate the knowledge they gained and they continue in further study.

Furthermore, opportunities for children with physical disabilities in order to participate in school or home settings have been the focus of many studies of ICT use. Such learners in order to access utilities software, is thought necessary the use of assistive devices such as touch screens, tracker balls, joysticks, keyboards and mouse alternatives [16] . Students with motor disabilities have different capabilities and needs and so ICT can play an essential role as an inclusion tool in school. Nevertheless, Douglas et al [9] support the view that in order for an ICT intervention tool to be effective it is always significant to discuss before implementing any adaptations to practice.

Hornof and Cavender [17] introduced the 'EyeDraw' software program which, with an eye tracking device, enables individuals with severe motor impairments to draw with their eyes. This method has been tested successfully on children and young adults with and/or without disabilities and despite the fact that might be difficult to use at first it gets easier with the practice as children receive constant caregiver's attention from the first session.

Also, Chen et al. [18] created CAT system, a computerized assessment tool which evaluates a child's pointing and selecting proficiency. This assessment module consists three sub-assessment systems and each one has its own purpose and assessment items.CAT system was developed and later it was modified to Mi-CAT tool that provides the professionals involved with multiple indicators relevant to the child's pointing and selecting performance. The developers claim that CAT system not only provides therapists with an objective means of evaluating child's specific mouse operating difficulties, but also al- 
lows them to compare the performance improvement made by the child during training period.

\section{LEARNING DIFFICULTIES}

\section{A. Children with difficulties in early literacy}

In kindergarten education, there have been conducted several studies that claim that properly designed digital educational activities can become an important educational tool for efficient and effective learning especially in the field of support of the early literacy skills [19] . A wide variety of ICT applications have become increasingly accepted as developmentally appropriate education resources for children's spoken and written language development requiring teacher assistance at some cases [20].

A number of researchers have studied the benefits of the computer assisted instruction (CAI), as an independent intervention, to support reading development in kindergarten children who face difficulties with the alphabet [21]. Many of the CAI programs have targeted phonological awareness, rhyming sound, segmenting, blending, alphabet skills, and concepts of print [22]. Cassady and Smith [23] found advantages of the Waterford Early Reading Program Level 1(WERP-1) in kindergarten classes. Their study claims that kindergartners in classes using WERP-1 obtained higher scores in phonological awareness and word reading than kindergartners in control groups.

Also, in a recently completed study, Macaruso et al [22] explored the benefits of a phonics-based CAI program for kindergartners, called Early Reading. The program provided systematic and structured exercises for developing phonological awareness and basic letter- sound correspondences and indicated that it offers an engaging format for all children, and especially to children who face difficulties to practice literacy skills, supporting them to progress independently at their own rate.

Moreover, according to Kegel et al. [24], computer programs can be used to stimulate early phoneme skills of poorly performing kindergarten children and can help children with poor regulatory skills(inhibitory control, working memory and cognitive flexibility). Although their current results show that children with poor regulatory and literacy skills did not benefit from the computer intervention they used (internet program called 'Living Letters), conclude saying that this program can be used as a diagnostic tool to detect poor regulatory skills in kindergarten children as well as a valuable teaching aid.

A similar experiment [25] reports the effect of the audio-visual training of voicing on a word recognition task among children with phonological disabilities with the teacher's guidance. Their findings suggest that the intervention improves the pre-reading skills of the experimental group and the children make progress in word recognition.

In a recent study, Toki et al [26] designed an online speech and language pathology system with the aim to provide the clinicians and other professionals with an additional tool on the diagnosis of disorders and difficulties in children's oral speech. The Internet based Speech Pathology Expert System in Greek, named APLO incorporates the user ability to answer certain questions and then it gives an automatic evaluating response and subsequently generates a list of weaknesses or disorders located. The study reports that this feedback can be used by the thera- pists and teachers to plan therapy or learning tasks supporting the child's needs in speech and language.

Also, Philips et al [27] introduced the emergent literacy screener, Get Ready to Read (GRTR) with the purpose to determine those children who may be at risk for later reading difficulties and could benefit from intervention and focused instruction in emergent literacy. The results of their experiment seem promising as the utility of the GRTR as a brief, valid measure of children's emergent literacy skills is thought a tool useful for educators, parents, and others in regular contact with kindergarten children. The study states that GRTR predicts scores on more comprehensive instruments for letter knowledge, phonological awareness, and print concepts, as is significantly related to measures of oral language, word and nonword reading and reading comprehension

\section{B. Children with difficulties in early maths}

It is well known that early years are the important years to develop children concepts and also critical and creative scientific thought [28]. A kindergarten child also needs the opportunity to apply its skills in a variety of learning environments, and is strongly recommended that the digital learning media can contribute to the learning of mathematical skills. Many aspects of early informal learning of mathematical concepts, such as numbers, arithmetic problem solving, and spatial syllogism along with general geometrical knowledge, are developed during the kindergarten age. Nevertheless, there is a growing corpus of research that suggests that the use of technological tools, as a representational modality, improves mathematics learning stating that interactive multimedia, such as multimedia CDs, and mobile devices can mediate learning through the provision of dynamic, visual representations [29].

An existing study[30], supports that "The Number Race" software trains children on an entertaining numerical comparison task, by presenting problems adapted to the performance level of the individual child, helping children with mathematical learning difficulties. The performance of the software was evaluated and the results indicate that the software adapts well to varying levels of initial knowledge and learning speeds as well as can be used to help children at risk for mathematical learning disabilities or with identified dyscalculia.

Furthermore, Goodwin [31] conducted a research and the results showed that the impact of interactive multimedia on kindergarten students, who have difficulties in representations of fractions, is significant. Specifically, the study states that the use of instructive tools (cds such as the Galaxy Kids Maths), constructive multimedia tools (such as Shape Fractions, developed by the Learning Federation) and constructive tools (such as Kidpix, Kidispiration and Create A Story) can aid children's performance. After the intervention, the kindergarteners seemed to be skilled at using symbol notation and at recognising quarters whereas some of them depicted mathematical concepts. Additionally, the researcher claimed that the immediacy of the feedback provided by the multimedia tools allowed for a quicker pace of learning than traditional inert representations and may account for the differences in the post-intervention responses between the two experimental groups.

Moreover, a recent study in the subject of mathematics, made a comparison between the learning outcomes of computer based teaching and mathematical thematic 
PAPER

teaching, aiming the teaching of "Realistic Mathematics" for kindergarten children. Compared to the traditional teaching method, results showed that computer-assisted learning enhance the development of mathematical skills and the cultivation of a deeper perceptual ability for the pupils who face or not problems [32] .

Additionally, Sarama and Clements [33] designed a development project, "Building Blocks", in order to enable all young children to build a solid foundation for mathematics, organised into two areas: (a) spatial and geometric competencies and concepts and (b) numeric and quantitative concepts. The research-based computer tools that stand at the base support the view that this program can connect children's informal knowledge to more formal school mathematics and can foster their mathematics skills with activities that need teacher's guidance and the partial use of the computer.

\section{Children at risk of dyslexia}

It is common knowledge that children with dyslexia require constant assistance to cope with the difficulties they face. Therefore, it is imperative to organize and implement systematic intervention methods in kindergarten age before these difficulties turn into specific symptoms of dyslexia in primary school, thus, losing valuable time to support the children who need it [34] . Helping children with learning difficulties has been a major concern of educational practice and so recent developments use ICT applications in order to support the learning needs of children at risk of dyslexia [35] .

According to a recent study the early indicators of developmental dyslexia in the kindergarten age are the psychomotor ability (body shape, laterality, spatio-temporal orientation, classification, temporal sequence, graphomotor ability), neuro-physiological development and cognitive mechanisms (auditory and visual perception, shortterm memory), the phonological awareness (recognition/perception/discrimination/processing of phonemes and graphemes), and the pre-reading and pre-writing skills[34] . "European Association of Dyslexia" estimates that $10 \%$ of population is suffering from dyslexia and only $30 \%$ of dyslexic children are identified before starting school or during the first academic year [3]. In kindergarten education according to Snowling et al [36] research has emphasised to the importance of early identification in pre-readers of a very young age of the precursors of dyslexic-type symptoms in order to facilitate the development of compensatory reading strategies. Indeed, Snowling [37] also suggests that with appropriate intervention, children with average oral comprehension skills and classic dyslexia symptoms, and also children with specific learning impairments in both oral and written comprehension, should be able to respond to appropriate teaching interventions, and become relatively normal readers. Finally, as Zakopoulou et al [34] report the detection of specific factors of the developmental dyslexia at an early stage, and the identification of the role of those factors responsible for its manifestation, is a fundamental area of study on dyslexia in the recent literature.

In a recent study [38] present the 'Phonological Awareness Educational Software' (PHAES) which is a hypermedia application for helping dyslexic or at risk children, using phonological awareness training. The PHAES learning activities use the small units of language (phoneme/grapheme) presented alone, at the word and sen- tence level, both in spoken and written format. Furthermore, the present research is aiming to aid children's literacy skills through phonological training as the theory suggests that phonological deficits constitute a core feature of dyslexia. According to this study, PHAES can be used without any difficulty or technical problems with and without adult's support whereas seems to be a highly motivating tool for young learners with or at risk of dyslexia. The developers state that PHAES is a tool not only useful for the special educator, but also for the mainstream teacher. Even though this software has been primarily designed as an intervention tool for students with dyslexia, it can also be used as a tool for assessing and children's successful mapping of letters and their corresponding sounds.

Moreover, a study that was conducted by Loizou and Laouris [39] showed that MAPS (Mental Attributes Profiling System) is a battery of computer based test that can assess the learning abilities of kindergarten and primary children. It consists of eight language independent tests that measure various aspects of learning, give a specific profile of each child and finally can identify their needs and decide the appropriate intervention. The researchers support the view that this diagnostic tool is a very good predictor tool for dyslexia and reading performance as it offers to specialists the help to pinpoint where problems may appear in the learning spectrum of a child.

In addition, Lucid Adult Development Screening (Lads) that was introduced by a research 40] is an objective computer-based system for identification of dyslexia between the ages of 4 to 15 years. It is swift and easy to administer, taking only 15 minutes - less than any comparable system currently available. Results, based on national standardized norms, are available immediately. A simple print-out of results, which incorporates automatic expert interpretation, gives clear indication of the probability of dyslexia in every case and differentiated recommendations for action.

Nevertheless, one of the most widely used software tools is the Cognitive Profiling System (CoPS), a computerized psychometric assessment system which identifies the cognitive strengths and difficulties for kindergarten and primary school children. CoPS is consisted of eight tests in the form of games, its total assessment time is no longer than twenty minutes and is used across the UK, Scotland and British schools around the world [41] . According to the developers, the students are tested in sequential and associative memory, auditory and colour discrimination and phonological awareness providing a snapshot of the child's level of development in the component areas at the time of school entry. Although not primarily intended for diagnostic purposes, it can nevertheless identify children who are weak in various aspects of learning and thus can be used to in decision-making about subsequent teaching and learning approaches for such children [41].

\section{Children with memory problems}

Close links between memory functions and many aspects of learning and academic achievement in children are well established[ 42]. Memory skills of children with special needs have been a domain of great research for professionals over the last years as there is evidence that shows that poor memory skills characterize children who fail to progress normally in different areas of needs 
PAPER

ICTS AND SPECIAL EDUCATION IN KINDERGARTEN

[2].However, it is well known that computerized programs seem to be a promising new approach to memory interventions.

In order to assist children with memory problems a tool called Cogmed was created[43]. There are three types of Cogmed training for preschoolers and older children and the designers indicate that this program is used in schools in order to assist children's performance and as a treatment of ADHD. The program includes several visuospatial and verbal memory tasks that have been embedded in videogames and is suggested to improve attention and working memory capacity of children. Although some studies indicated that Cogmed should improve reasoning abilities, after several studies it was proved that replications had failed. Moreover, it was noted that working memory capacity and performance may improve, although more research is needed to be done [43] .

Despite the fact that not many studies have explored the role of ICT in working memory and inhibition, in kindergarten children, Thorel et al. [44] report the role of a computerized training of visuo- spatial working memory and inhibition. The findings of their study suggest that children who trained on working memory improved significantly on trained tasks and children who trained on inhibition showed a significant improvement over time on two out of three trained task paradigms compared to the control group.

Additionally, Alloway presented the Automated Working Memory Assessment (AWMA), a standardised computerized tool. This tool enables teachers and psychologists to assess working memory skills with a user-friendly interface. AWMA includes three levels of assessment and is designed for students with suspected working memory difficulties. Specifically, AWMA: Short Form (AWMAS) is used for screening learners who are suspected to have memory deficits, but the specific area of their difficulties is not known and AWMA: Long Form (AWMA-L) is suitable for confirmation of working memory problems for learners identified as having working memory problems in the classroom[45].

\section{E. Children with $A D H D$ and $A D$}

Children with attention deficit hyperactivity disorder (ADHD) experience effusive interpersonal difficulties and peer disapproval that go beyond the diagnostic criteria. ADHD occurs in approx $3-5 \%$ of the school-aged population, with male to female ratios ranging from $4: 1$ to $9: 1$, depending on the setting. The disorder persists into adolescence in about $50-80 \%$ of cases clinically diagnosed in childhood and basic characteristics of the disorder include inattention, hyperactivity, and impulsivity[46]. Although minimal research has been done on the effectiveness of technology for students with ADHD, technology is seen as one potential tool that offers promising results for these students. Technology enables the teacher to plan learning activities for students with short attention spans, allowing them to be actively involved in learning, and in turn even increase the student's motivation and confidence [47] .

In the light of the above statements and with regards to computer assistance instructions (CAI), latest studies support that children with ADHD prefer to read short texts and watch short videos that include not many words [48]. Also, the words should be used only for explanatory reasons, visual aids should be used to illustrate and support verbal information, and the rate of presentation should be slow. Additionally, low lights are suggested rather than bright lights for ADHD in order to concentrate on tasks [48].

Moreover, a recent study [49] presents the effects of a proposed CAI Module in Numeracy for kindergarten children with ADHD. The study is a developmental research whose primary goal was to develop a CAI Module on enhancing the numeracy skills of kindergarteners with ADHD based on the ARCS Model of Motivational Design by Keller \& Keller following the ADDIE Model of Instructional System Design by McArdle. The program allows each student to work with the Module for twenty minutes per session, asks each child to select and perform the task in the CAI Module and records the physical and verbal reactions of each student. According to this study, it can be concluded that the promising results of technology are aligned with the inattention, impulsivity, and hyperactivity symptoms of students with ADHD despite the fact that further improvements can still be incorporated to the proposed CAI Module.

Another example of a CAI intervention was studied by Clarfield and Stoner [50], which examined the effects of the Internet based reading program, Headsprout, on the academic performance of students with ADHD. The participants for this study were males in kindergarten and first grade who were diagnosed with ADHD and considered at risk for reading difficulties by their teachers. The data for this study indicated that the effects of CAI on oral reading fluency were improved for all the students and has been shown an increase active engagement time and decrease off task behaviour in children. Overall, the research supported the hypothesis that Headsprout would work as an appropriate and effective intervention for beginning readers with ADHD.

\section{F. Children with autistic spectrum disorder}

One category within the group of 'Developmental Disorders' is known as Autistic Spectrum Disorders (ASD) which are a set of developmental problems that affect child's social and communication skills. Today, as a result of research is that the use of ICTs has gathered accumulative evidence around it. The diagnosis of autism or the rest of the ASD is in most of the times a result of the several traditional assessment tests that are available to professionals. However, the latest years, important attempts have been made in the field of ICT assessment because teaching kindergarten children with autism requires special set of tools and methods due to their impaired social interaction and communication, and their repetitive, self-stimulating restricting behaviours [51].

Hulusic and Pistoljevic [52] developed the LEFCA framework for teaching children with autism basic skills and concepts. The results of their preliminary study showed that the specific software in native language is completely clear and user friendly for kids with Autism and other special needs, and that is systematically and developmentally appropriate for learning without any needed training.

Tseng, Yi-Luen and Do [53] presented a novel design prototype ICT application for children with ASD. The Facial Expression Wonderland (FEW) application is designed to improve the ability of ASD learners in facial expression recognition and is a daily training tool which consists of different levels. Moreover, requires learners with ASD to play in an everyday basis in order to improve 
PAPER

their skills in facial expression recognition according to the 'Theory of Mind' (the ability to understand mental status of other people). However, the real impact of FEW applications is not yet evaluated and is to be estimated in the future.

In the same year Tanaka et al [54] designed a computerbased intervention relevant to the above the 'Let'sFace It!' program. This program is consisted of seven interactive computer games which aim at the specific face impairments associated with the condition of autism. This method has been tested on children diagnosed with ASD who received a twenty hours of training with the program. It is an intervention method which can be easily implemented in home and /or school setting without direct supervision with encouraging results.

\section{GIFTED CHILDREN}

Young gifted children perform in the top $10 \%$ in assessments of cognitive, social, expressive or other abilities. Researchers state that gifted performance is based on interactions between above average general abilities and high levels of task commitment and creativity [55]. Mooij [55] emphasises, that ICT educational programmes for gifted pupils should focus on fostering multilevel instructional and organisational characteristics underlying that for kindergarten gifted children important conditions are the direct and integrated availability of curricular resources and materials suitable for the full spectrum of development and learning levels of all pupils.

According to a recent study [56]internet-based information and communication technology (ICT) can assist in registering, integrating, evaluating, and reporting instructional, learning, and evaluation processes in various ways gifted children in kindergarten. Mooij also developed a psychometrically controlled screening procedure-for both parents and teachers-that estimates a child's level by comparing the child's behaviour with the behaviour of sameage peers. The resulting information can be used to check and compare the parents' and kindergarten teachers' views of the child as well as to select and design appropriate play materials or instructional lines according to child's level [56].

Additionally, Cukierkorn et al [57] suggest that gifted children should synthesize their learning, proposing that children's work may be scanned and placed into a PowerPoint presentation, allowing the student to choose slide design styles, create slide titles, and add text. They continue saying that these presentations can then be shared with other students and parents or published on the Web; this is why gifted children can improve their skills and feel comfortable when they exchange information with each other.

Finally, the view of Clark [58] is that young gifted children respond well to multiple learning centres such as art, science, reading, writing, and building. Bright wall displays, multimedia technology, animals, and plants should also be featured in a combination of both private spaces and shared public spaces in order to foster their learning.

\section{Bilingual ChILdREN}

In countries with a high proportion of immigrants, the cultural integration of second-generation immigrants is a key issue. One way of fostering such integration is to extend early bilingual education. Some literature suggests that bilingual programmes for young children may actually result in better learning outcomes than total immersion programmes. Although bilingual programmes are rare, some are likely to be beneficial as they provide concurrent support for language and content learning [59].

A recent study discusses teaching strategies, including the use of ICTs, identified by teacher-researchers as supporting their goal to improve learning and teaching for all children in the intercultural setting of a kindergarten in Aotearoa New Zealand ; the specific intercultural setting involves Samoans (Pacific Island people), Maori (indigenous New Zealanders) and European New Zealanders. The findings suggest that effective bilingual programmes for young children demand both working with the cultural practices of the specific language communities involved, and identifying strategies that allow a wider range of adults to participate as members of the extended community of learners. Specifically, the Power Point stories that were used made up both collaborative activity and an innovative product of learning at the same time promoting acquisition of relevant digital, linguistic and book-reading skills. Furthermore, the Samoan language and cultural learning inserted in the shared activities seems likely to have positive outcomes in a multi-cultural society such as Aotearoa. Simultaneously, positive intercultural attitudes were evident as children enjoyed each other's cultural practices and created new shared meanings in Power Point and e- book forms to present their experiences [60].

Another study examines the impact of the use of electronic stories that results in the literacy development of kindergartners who learn English as a second language[61]. This project was designed as a technological intervention to study the role of CD-ROM stories and storytelling applications delivered via a computer in the development of literacy skills of Spanish-speaking children. The children participated in a total of 12 lessons spread out in three weeks and worked with three traditional stories from the series of Inside Stories. The two main objectives of the project were to explore whether language lessons based on CD-ROM stories and the storytelling approach would lead to the development of emergent literacy skills of young children and the views of the teachers on the inclusion of ICT in the classroom. The study provided evidence that the use of ICT-stories enhanced the learning environment of the language lesson by increasing the motivation of children, observed in their level of participation and their response to the stories. Engagement of the children with the ICT tasks and their level of comprehension of the stories provided evidence of the potential of this type of material for the language classroom. Finally, animations and sounds helped the children to construct meaning from the stories and as a result, the language in which the stories were told did not produce any observable negative effects on the children.

\section{CONCLUSION}

The scope of this study was to present if and how new technology can support kindergarteners with special educational needs. The findings of the studies we examined, which are the most representative studies over the last decade, showed that kindergarteners can benefit of the use of new technology and can gain many advantages and profits using the appropriate educational tools that offers the use of ICT. The use of ICT has also played a major part in shaping the knowledge and skills of school staff, 
therapists and special educators. Diagnostic tools provide them with the possibility to employ different ICT strategies which might lead to an easier understanding of children's learning differences while ICT intervention tools support activities of kindergarteners' life. In general, the use of ICTs in special education including children with physical and sensory disabilities, learning difficulties, gifted and bilingual children is considered crucial in the early years, besides that further research in this sensitive domain is thought necessary. However, there are also several fields that require further research such as investigations into the reliability and validity of the diagnostic ICT tools, adaptations of diagnostic and intervention tools to the various needs of students of the therapists, and development of more ICT programs for the above areas in the specific crucial age. Finally, we consider that the field of kindergarten education (children, teachers, parents and classrooms) and the interventions that ICTs can contribute in many areas of child's development calls for more research hoping that the results of the current study are encouraging as there is the general consensus that ICTs do play a significant role in both ensuring and enhancing learning skills of kindergarten children who need special educational support.

\section{REFERENCES}

[1] Aktas -Arnas, Y.: Computer-Assisted Instruction In Pre-School Education. Eurasian Journal of Educational research 20, pp 3647 (2005)

[2] Drigas, A., Ioannidou, R.E.:ICTs in Special Education: A Review. In: M.D. Lytras et al. (Eds.): WSKS 2011, Vol. 278, pp. 357-364 Springer-Verlag Berlin Heidelberg (2013)

[3] Stevens, C.: Information and communication technology, special educational needs and schools: a historical perspective of UK government initiatives. In: Florian, L., Hegarty, J. (eds.) ICT and Special Educational Needs: a Tool for Inclusion, pp. 21-34. Open University Press, Buckingham (2004)

[4] Plowman, L., Stephen, C.: Children, play, and computers in preschool education. British Journal of Educational Technology 36 (2), pp. 145-157 (2005) http://dx.doi.org/10.1111/j.14678535.2005.00449.x

[5] BEC TA: A review of the evidence on the use of ICT in the Early Years Foundation Stage. (2008) Available also on-line: http://www.becta.org.uk

[6] Meijer, C., Soriano, V., Watkins, A: Inclusive Education across Europe: Reflections upon 10 Years of Work from the European Agency for Development in Special Needs Education Childhood Education 83(6), p361-374 (2007)

[7] Department for Education and Skills, Special Educational Needs Code of Practice. London: DfES, (2001)

[8] Westwood, P: Teaching and Learning Difficulties: Crosscurricular Perspectives. Camberwell, ACER Press (2006)

[9] Douglas, G., Long, R.: An observation of adults with visual impairments carrying out copy-typing tasks. Behaviour \& IT , 22(3),pp.141-153, (2003)

[10] Raisamo, R.,Hippula, A., Patomaki, S., Tuominen, E., Pasto, V., Hasu, M.: Testing Usability of Multimodal Applications with Visually Impaired Children," IEEE Multimedia, 13, (3), pp. 70-76, (2006) http://dx.doi.org/10.1109/MMUL.2006.68

[11] Sanchez J., Saenz, M.,\& Carrido,J.: Usability of a Multimodal Video Game to Improve Navigation Skills for Blind Children. ACM Transactions on Accessible Computing, 3, (2), pp. 1-29 (2010) http://dx.doi.org/10.1145/1857920.1857924

[12] Margolis, R.H., Glasberg, B.R., Creeke : AMTAS: Automated method for testing auditory sensitivity: Validation studies. International Journal of Audiology, 49(3), pp.185-194 (2010) http://dx.doi.org/10.3109/14992020903092608

[13] Korte, J., Potter,L.,Nielsen,S.: Designing a mobile video game to help young deaf children learn Auslan. People \& Computers XXVI, 345-361 Birmingham, UK (2012)
[14] Yen,S., Lee, M. : Voice Gesture Framework in Digital Interactive Storybook for Hearing-impaired Pre-schooler. Journal of speech and hearing disorders 48 (1), 40-143 (2010)

[15] Drigas, A.S., Kouremenos, D., Kouremenos, S. and Vrettaros, J.: An e-Learning System for the deaf people. Information Technology Based Higher Education and Training, ITHET 6th Annual International Conference, 2005.

[16] William,P.,Jamali, H., Nickolas,D. :Using ICT with people with special education needs: what the literature tells us. New Information Perspectives 58(4), 330-345 (2006)

[17] Hornof, A. and Cavender, A.: EyeDraw: enabling children with severe motor impairments to draw with their eyes. CHI '05 Proceedings of the SIGCHI conference on Human factors in computing systems, pp. 161-170, (2005).

[18] Chen, M., Chu, C, Yeh, C.: Computerized Assessment Approach for Evaluating Computer Interaction Performance. In K. Miesenberger et al. (Eds.): ICCHP 2006, LNCS 4061, pp. 450 - 456, Springer-Verlag Berlin Heidelberg 2006

[19] Plowman,L.,Stephen,C. and McPace,J. :Supporting young children's learning with technology at home and in preschool". Research paper in Education 25, p.93-113(2010) http://dx.doi.org/10.1080/02671520802584061

[20] Segers, E., Verhoeven,L. : Long-term effects of computer training of phonological awareness in kindergarten. Journal of Computer Assisted Learning 21, 17- 27 (2005) http://dx.doi.org/10.1111/ j.1365-2729.2005.00107.x

[21] Yelland, N. "The future is now: A review of the literature on the use of computers in early childhood education (1994-2004)." AACE Journal, 13, p. 201-232 (2005)

[22] Macaruso, P., Walker, A.: The Efficacy of Computer- Assisted Instruction for Advancing Literacy Skills in Kindergarten Children. Reading Psychology 29, pp. 266-287 (2008) http://dx.doi.org/10.1080/02702710801982019

[23] Cassady, J., Smith, L.: The Impact of a Structured Integrated Learning System on First Grade Students' Reading Gains. Reading \& Writing Quarterly: Overcoming Learning Difficulties 21 (4), pp. 361-376 (2005) http://dx.doi.org/10.1080/10573560591002277

[24] Kegel, C., van der Kooy-Hofland, V., Bus, A.: Improving early phoneme skills with a computer program: Differential effects of regulatory skills. Learning and Individual Differences 19, 549554(2009) http://dx.doi.org/10.1016/j.lindif.2009.07.002

[25] Magnan, A., Ecalle,J., Veuillet,E., \& Collet,L.: The Effects of an Audio-Visual Training Program in Dyslexic Children. DYSLEXIA 10, pp. 131-140(2004) http://dx.doi.org/10.1002/ dys. 270

[26] Toki,E., Pange,J., Mikropoulos, T.: An online expert system for diagnostic assessment procedures on young children oral speech and language. Procedia Computer Science 14, pp. 428 - 437 (2012) http://dx.doi.org/10.1016/j.procs.2012.10.049

[27] Phillips, B., Clancy-Menchetti,J., and Lonigan, C. : Successful Phonological Awareness Instruction With Preschool Children: Lessons From the Classroom. Topics in Early Childhood Special Education. 28(3), pp.1-16 (2008)

[28] Saracho,O.,\& Spodek,B. :" Educating the Young Mathematician: The Twentieth Century and beyond" Early Childhood Education, 36,p.305-312 (2008)

[29] Laborde, C., Kynigos, C., Hollebrands, K. \& Strasser, R. (2006). Teaching and learning geometry with technology. In A. Gutierrez \& P. Boero (Eds.), Handbook of research on the psychology of mathematics education: Past, present and future (pp. 275-304). Rotterdam. The Netherlands: Sense Publishers

[30] Wilson,A., Revkin,S, Cohen,D., Cohen,L., and Dehaene,S.: An open trial assessment of "The Number Race", an adaptive computer game for remediation of dyscalculia. Behavioral and Brain Functions, 2(20), pp.1-16 (2006)

[31] Goodwin,K.: The impact of interactive multimedia on kindergarten students' representations of fractions. Issues in Educational Research, 18(2), pp.103-117 (2008)

[32] Zaranis,N.: The influence of ICT on the numeracy achievement of Greek kindergarten children. In Moreira, M., Loureiro,J., Balula, A., Nogueira,F., Pombo,L., Pedro, L., \& Almeida,P. (Eds.) Proceedings of the 61 st International Council for Educational Media and the XIII International Symposium on Computers in Education 
(ICEM\&SIIE'2011) Joint Conference (pp. 390-399), University of Aveiro, Portugal, 28-30 September 2011.

[33] Sarama,J., Clements, D.: Building Blocks for early childhood mathematics." Early Childhood Research Quarterly 19, pp .181189 (2004)

[34] Zakopoulou,V., Anagnostopoulou,A. Christodoulides,P., Stavrou,L. Sarri,I., Mavreas,V.,\& Tzoufi,M.: An interpretative model of early indicators of specific developmental dyslexia in preschool age: A comparative presentation of three studies in Greece. Research in developmental Disabilities.32, pp3002-3013 (2011) http://dx.doi.org/10.1016/j.ridd.2011.03.021

[35] Lee,Y\& Vail,S. : Computer-Based Reading Instruction for Young Children with Disabilities. Journal of Special Education Technology, 20 (1), pp. 1-15 (2005)

[36] Snowling, M. J., Muter, V., \& Carroll, J. M.: Children at family risk of dyslexia: A follow-up in adolescence. Journal of Child Psychology \& Psychiatry, 48, pp. 609-618(2007) http://dx.doi.org/10.1111/j.1469-7610.2006.01725.x

[37] Snowling,M.:Specific disorders and broader phenotypes: The case of dyslexia, The Quarterly Journal of Experimental Psychology 61 (1), pp.142-156 (2008) http://dx.doi.org/10.1080/17470 210701508830

[38] Kazakou, M., Soulis,S., Morfidi, E., Mikropoulos,T.: Phonological Awareness Software for Dyslexic Children. Themes in Science \& Technology Education, 4(1), 33-51 (2011)

[39] Loizou,A. Laouris, Y. : Developing Prognosis Tools to Identify Learning Difficulties in Children Using Machine Learning Technologies. Cognition and Computers 3, 490-500(2011) http://dx.doi.org/10.1007/s12559-010-9052-5

[40] Singleton, C., Horne,J., Leedale,R. Thomas,K.: Lucid Rapid Dyslexia Screening Administration. Interpretation and Teaching Guide First Edition, February 2003

[41] Singleton. : Using computer-based assessment to identify learning problems. In: ICT and Special Educational Needs, L. Florian and J. Hegarty, Eds, Open University Press pp. 46-63(2004)

[42] Gathercole , S., Willis , C., Baddeley,A., Emslie, H. : The children's test of nonword repetition: A test of phonological working memory. Memory 2 (2),103-127 (2007) http://dx.doi.org/10.1080/ 09658219408258940

[43] Shipstead,Z., Hicks, K., Engle,R.: Cogmed working memory training: Does the evidence support the claims? Journal of Applied Research in Memory and Cognition 1, 185-193 (2012) http://dx.doi.org/10.1016/j.jarmac.2012.06.003

[44] Thorell,L., Lindqvist,S, Bergman,S, Bohlin,G., Klingberg,T. Training and transfer effects of executive functions in preschool children. Developmental Science 11(6), p p 969-976 (2008)

[45] Alloway, T. P., Gathercole, S. E., Kirkwood, H. and Elliot, J.: The working memory rating scale: A classroom-based behavioral assessment of working memory, Learning and Individual Difference, 19 (2), pp. 242-245(2009) http://dx.doi.org/10.1016/ j.lindif.2008.10.003

[46] McGoey, K., Eckert,T.,Dupaul,G.: Early Intervention for Preschool-Age Children with ADHD: A Literature Review. Journal of Emotional and Behavioral Disorders 10 (14), 14-28 (2002) http://dx.doi.org/10.1177/106342660201000103

[47] Fen Gau, S., Chiang,H.L.: Association between early attentiondeficit/hyperactivity symptoms and current verbal and visuospatial short-term memory. Research in Developmental Disabilities $\quad 34, \quad 710-720(2013) \quad$ http://dx.doi.org/10.1016/j.ridd. 2012.10.005

[48] Solomonidou, C., Garagouni-Areou, F. \& Zafiropoulou, M. : Information and Communication Technologies (ICT) and Pupils with Attention Deficit Hyperactivity Disorder (ADHD) Symptoms: Do the Software and the Instruction Method Affect Their Behavior?.Journal of Educational Multimedia and Hypermedia, 13(2), pp.109-128 (2004)

[49] Alontaga,J :A computer-assisted instruction module on enhancing numeracy skills of preschoolers with attention-deficit hyperactivity disorder. International Journal of Information Technology and Business Management 2(1), 1-15 (2012)

[50] Clarfield, J.,\& Stoner,G : Research Brief: The Effects of Computerized Reading Instruction on the Academic Performance of Students Identified with ADHD. School Psychology Review 34(2), pp.246-254 (2005)
[51] Karagiannidis, C., Chatzara,K., Stamatis, D. : Structural learning through digital storytelling for people with autism. In: C. Karagiannidis, P. Politis \& I. Karasavvidis (eds.), Proceedings of the 8th Pan-Hellenic Conference with International Participation «ICT in Education» University of Thessaly, Volos, Greece, 28-30 September 2012

[52] Hulusic,V., Pistoljevic,N.: "LeFCA": Learning framework for children with autism. Procedia Computer Science 15, $4-16$ (2012) http://dx.doi.org/10.1016/j.procs.2012.10.052

[53] Tseng, R., Yi-Luen and Do, E.: Facial Expression Wonderland (FEW) - A Novel Desing Prototype of Information and Computer Technology (ICT) for Children with Autism Spectrum Disorder (ASD). 1st ACM IHI Symposium, Virginia, USA, 2010.

[54] Tanaka J.W., Wolf J.M., Klaiman C., Koenig K., Cockburn J., Herlihy L., Brown C., Stahl S., Kaiser M.D., Schultz R.T.: Using computerized games to teach face recognition skills to children with autism spectrum disorder: the Let's Face It! program. The Journal of Child Psychology and Psychiatry, 51(8),pp. 944-95, (2010) http://dx.doi.org/10.1111/j.1469-7610.2010.02258.x

[55] Mooij,, T.: Design of educational and ICT conditions to integrate differences in learning: Contextual learning theory and a first transformation step in early education. Computers in Human Behaviour 23 (3), pp. 1499-1530 (2007) http://dx.doi.org/10.1016/ j.chb.2005.07.004

[56] Mooij, T.: Designing instruction and learning for cognitively gifted pupils in preschool and primary school. International Journal of Inclusive Education 17(6), pp. 597-613 (2013) http://dx.doi.org/10.1080/13603116.2012.696727

[57] Cukierkorn J., Karnes, F., Manning, S. Houston, H., Besnoy,K.: Serving the preschool gifted child: Programming and resources. Roeper Review, 29(4), 271-276(2007) http://dx.doi.org/10.1080/ 02783190709554422

[58] Clark, D. A.: Development Ethics: A Research Agenda. International Journal of Social Economics 29 (11), pp. 830-848 (2002) http://dx.doi.org/10.1108/03068290210446258

[59] Baker,C.: Bilingual Education University of Wales, Bangor, North Wales, UK (2006)

[60] Cullen , J., Haworth ,P., Simmons ,H., Schimanski ,L., McGarva, P., Kennedy, E. Teacher-researchers promoting cultural learning in an intercultural kindergarten in Aotearoa New Zealand. Language, Culture and Curriculum 22(1), 43-56 (2009) http://dx.doi.org/10.1080/07908310802582511

[61] Saucedo, A.: Exploring the impact of using stories and Ict to teach English to three and four year old Spanish children: motivation and development. Contemporary Issues in Early Childhood, 3 (2), 161-181(2005)

\section{AUTHORS}

Athanasios Drigas is a Senior Researcher at N.C.S.R. Demokritos. He is the Coordinator of Telecoms Lab and founder of Net Media Lab since 1996. From 1985 to 1999 he was the Operational manager of the Greek Academic network. He has been the Coordinator of Several International Projects, in the fields of ICTs, and e-services (elearning, e-psychology, e-government, e-inclusion, eculture etc). He has published more than 200 articles, 7 books, 25 educational CD-ROMs and several patents. He has been a member of several International committees for the design and coordination of Network and ICT activities and of international conferences and journals. (e-mail: dr@iit.demokritos.gr).

Georgia Kokkalia (MSc in Specific Learning Difficulties) is a Special Education Teaching Professional. She has participated in various research projects regarding the use of Information and Communication Technologies (ICTs) in Special Education and in Kindergarten. (e-mail: gioulina@hotmail.com).

Submitted 18 March 2014. Published as resubmitted by the authors 14 June 2014. 